\title{
Biochemical hepatic alterations and body lipid composition in the herbivorous grass carp (Ctenopharyngodon idella) fed high-fat diets
}

\author{
Zhen-Yu Du ${ }^{1,2}$, Pierre Clouet ${ }^{2}$, Wen-Hui Zheng ${ }^{3}$, Pascal Degrace ${ }^{2}$, Li-Xia Tian ${ }^{1}$ and Yong-Jian Liu ${ }^{1}$ \\ ${ }^{1}$ Institute of Aquatic Economic Animals, School of Life Sciences, Sun Yat-sen University, 510275 Guangzhou, China \\ ${ }^{2}$ UPRES Lipides et Nutrition EA2422, Université de Bourgogne, 21000 Dijon, France \\ ${ }^{3}$ The Research Centre of Molecular Medicine, Medicine School, Sun Yat-sen University, 510089 Guangzhou, China
}

(Received 23 February 2005 - Revised 22 November 2005 - Accepted 20 December 2005)

\begin{abstract}
High-fat diets may have favourable effects on growth of some carnivorous fish because of the protein-sparing effect of lipids, but high-fat diets also exert some negative impacts on flesh quality. The goal of the study was therefore to determine the effects of fat-enriched diets in juvenile grass carp (Ctenopharyngodon idella) as a typical herbivorous fish on growth and possible lipid metabolism alterations. Three isonitrogenous diets containing 2,6 or $10 \%$ of a mixture of lard, maize oil and fish oil (1:1:1, by weight) were applied to fish for 8 weeks in a recirculation system. Data show that feeding diets with increasing lipid levels resulted in lowered feed intake, decreased growth and feed efficiency, and increased mesenteric fat tissue weight. Concomitantly, alteration of lipoprotein synthesis and greater level of lipid peroxidation were apparent in blood. In liver, muscle and mesenteric fat tissue, the percentages of $\alpha$-linolenic acid and DHA were significantly increased or tended to increase with higher dietary lipid levels. Biochemical activity measurements performed on liver showed that, with the increase in dietary lipid level, there was a decrease in both mitochondrial and peroxisomal fatty acid oxidation capacities, which might contribute, at least in part, to the specific accumulation of $\alpha$-linolenic acid and DHA into cells more active in membrane building. On the whole, grass carp have difficulty in energetically utilising excess dietary fat, especially when enriched in $n-3$ PUFA that are susceptible to peroxidation.
\end{abstract}

Grass carp: High-fat diets: Lipid composition: $\beta$-Oxidation

The use of lipid-rich diets of high energetic value is the current trend in aquaculture. Dietary fats play a prominent role in fish nutrition to provide essential fatty acids necessary to biological structure and normal function of cell membranes (Sargent et al. 1999). Within certain limits, increasing the lipid level in diets improves the utilisation of food (Watanabe et al. 1979; Johnsen et al. 1993; Peres \& Oliva-Teles, 1999a). Indeed, dietary lipids were reported to exert a protein-sparing effect by replacing protein that can be used for the production of energy (Watanabe, 1982; Beamish \& Medland, 1986), which was highlighted by the reduced $\mathrm{N}$ losses in carnivorous fish species (Lee \& Putnam, 1973). However, in some species, the interest in increasing dietary fat level must be evaluated very carefully. Indeed some reports showed that high-fat diets led to increased fat deposition in fish (Stowell \& Gatlin, 1992; Arzel et al. 1994; Stephan et al. 1996; Lee et al. 2002), induced metabolic alterations, including fatty liver (Dos Santos et al. 1993), led to abnormal oxidative status (Rueda-Jasso et al. 2004) and impairments of nutritional value and transformation yield, as well as affecting organoleptic and physical properties (Austreng \& Krogdahl, 1987; Gjedrem, 1997; Hillestad et al. 1998).

As a typical herbivorous finfish, grass carp (Ctenopharyngodon idella) can eat artificial diets in aquaculture as well as water plants in its natural environment. Takeuchi (1996) reviewed the essential fatty acid requirement of grass carp and pointed out that the requirement of dietary $n-6$ and $n-3$ fatty acids was between 0.5 and $1 \%$ of the diet. Lin (1991) also reviewed the nutrient requirements of grass carp and underlined from primary experiments that grass carp does not require large amounts of lipids. Reevaluations regarding the effects of dietary fat level showed that the energy requirement of grass carp was relatively lower than that of most carnivorous fish species, that the protein-sparing effect was effective only below $4 \%$ of lipid in the diet and that $6 \%$ of dietary lipid was already sufficient to negatively affect growth performance and body composition (Du et al. 2005). This result was surprising because most fish species, especially carnivorous fish, can easily utilise above $10 \%$ dietary lipid without any negative effects on growth (Arzel et al. 1994; Luzzana et al. 1994; Peres \& Oliva-Teles, 1999b). The aim of the present study was therefore to determine, in the herbivorous grass carp, the effects of increasing dietary lipid level on growth performance, body fatty acid composition and hepatic fatty acid oxidation, in an attempt to clarify the mechanisms associated with the negative effects of high fat intake. 


\section{Materials and methods}

\section{Diet preparation}

The formulation of the three purified diets (L2, L6 and L10) detailed in Table 1 was carried out with products all originating from the mainland of China. All the dry ingredients were mixed for $15 \mathrm{~min}$ and then the oil mixture composed of lard, purified maize oil and fish oil (1:1:1, by weight) was added and mixed for another $15 \mathrm{~min}$. Water (about $30 \%$ DM) was then added and mixed again for another $15 \mathrm{~min}$. The wet mixture was transformed into $1.5 \mathrm{~mm}$ pellets in a F-26 Pelleter (SCUT Factory, Guangzhou, China), air-dried with a common fan at room temperature for $24 \mathrm{~h}$, and stored at $-20^{\circ} \mathrm{C}$ until use. The available energy for protein, carbohydrate and lipid was calculated using the physiological fuel value of $16.74,16.74$ and $37.66 \mathrm{~kJ}(4.0,4.0$ and $9.0 \mathrm{kcal}) / \mathrm{g}$, respectively (Lee \& Putnam, 1973; Garling \& Wilson, 1977).

\section{Supply and maintenance of fish}

Juvenile grass carp were maintained in nine circular 120 litre fibreglass tanks which were inter-connected as a closed recirculation system containing freshwater at the Fish Nutrition Laboratory, Sun Yat-sen University (Guangzhou, China). A natural light cycle was used in the whole experimental period. Fish were acclimatised to experimental conditions for 2 weeks, during which they were fed the

Table 1. Composition of experimental diets (\% dry weight)

\begin{tabular}{lccc}
\hline & \multicolumn{3}{c}{ Experimental diets } \\
\cline { 2 - 4 } & L2 & L6 & L10 \\
\hline Ingredients & & & \\
Casein & 28 & 28 & 28 \\
Gelatin & 7 & 7 & 7 \\
Dextrin & 25 & 25 & 25 \\
Oil mixture & 2 & 6 & 10 \\
Cellulose & 26 & 22 & 18 \\
Vitamin mix & 2 & 2 & 2 \\
Mineral mix & 8 & 8 & 8 \\
Ascorbic phosphate ester & 1 & 1 & 1 \\
Choline chloride & 0.5 & 0.5 & 0.5 \\
Proximate composition & 35.1 & 35.7 & 35.3 \\
Crude protein & 1.9 & 5.9 & 9.9 \\
Crude lipid & 23.8 & 24.1 & 24.3 \\
Carbohydrate§ & 9.8 & 11.1 & 12.0 \\
Moisture & 5.9 & 5.8 & 6.0 \\
Ash & 10581 & 12217 & 13686 \\
Available energy (kJ/kg) & & \\
\hline
\end{tabular}

${ }^{*}$ Consisted of lard (Tongwei Feed, Chengdu, China), maize oil (Taishan Feed, Zhongshan, China) and purified fish oil (Haiyuan Bio-Sci, Qingdao, China) (1:1:1, by weight).

† Vitamin mix (Chenyi Feed, Guangzhou, China) contained ( $\mathrm{mg} / 100 \mathrm{~g}$ diet): thiamine, 5; riboflavin, 5 ; vitamin $A, 0.875$; vitamin $E, 40$; vitamin $D_{3}, 0.06$; menadione, 4; pyridoxine $\mathrm{HCl}$, 4; cyanocobalamin, 0.01; biotin, 0.6; calcium pantothenate, 10; folic acid, 1.5; niacin, 20; inositol, 200. Cellulose was used as a carrier.

$\ddagger$ Mineral mix contained (Chenyi Feed, Guangzhou, China) (g/100 g diet): calcium biphosphate, 0.98; calcium lactate, 3.79; sodium chloride, 0.26 ; potassium sulfate, 1.31; potassium chloride, 0.53 ; ferrous sulfate, 0.09 ; ferric citrate, 0.31 ; magnesium sulfate, 0.35; zinc sulfate, 0.004; manganese sulfate, 0.003; copper sulfate, 0.002; cobalt chloride, 0.003 ; potassium iodide, 0.0002 ; cellulose, 4.2 .

$\S$ Cellulose not included. lipid-free experimental diet (gross energy $9673 \mathrm{~kJ}$ $(2312 \mathrm{kcal}) / \mathrm{kg}$ diet) at $1 \%$ of body weight per d. For the experiments, fish with similar body weights were selected and randomly distributed into the nine-tank system with seventeen fish per tank. All fish were weighed, the differences in body weight being less than $5 \%$ for each tank. The initial mean weight was 4.06 (SEM $0.05) \mathrm{g}$. Grass carp were fed by hand at 09.00 and 18.00 hours with equal portions of diet. The feeding rate was $3-4 \%$ body weight/d. Fish were weighed with water once every 2 weeks over the $56 \mathrm{~d}$ of the experimental treatment, and the daily rations were adjusted accordingly. The wasted diet and faeces were removed from the tanks using a rubber pipe every morning and were dried for feed intake corrections. Throughout the experimental period, water temperature, dissolved $\mathrm{O}_{2}, \mathrm{pH}$ and ammonia were maintained at about $28.3^{\circ} \mathrm{C}, 7.6 \mathrm{mg} / \mathrm{l}, \quad 7.1$ and $0 \cdot 13 \mathrm{mg} / \mathrm{l}$, respectively.

\section{Growth performance and chemical analysis}

Before the beginning of the experimental period, twelve fish fasted for $24 \mathrm{~h}$ were randomly divided into three groups (four fish per group) for the initial measurements. As the results obtained from four fish were pooled, the number of different results was equal to three (n 3). After a $56 \mathrm{~d}$ trial, three $24 \mathrm{~h}$-fasted fish were randomly captured from each tank for whole-body chemical analyses and calculations of protein efficiency, protein retention and lipid retention (see Table 2). Other five fish from each tank were killed by spinal destruction, weighed and measured for the determination of weight gain, specific growth rate, feed efficiency and condition factor. They were also dissected for the calculation of viscera index, hepatosomatic index and mesenteric fat index (MFI). Pieces of liver, mesenteric fat tissues and muscles of both sides of spine (fillets) without skin were stored at $-20^{\circ} \mathrm{C}$ until analysis. Tissue moisture was measured by drying at $105^{\circ} \mathrm{C}$ for $24 \mathrm{~h}$. Total $\mathrm{N}$, carbohydrate, and ash of diets and body samples were analysed by the Kjeldahl method with a Tecator Kjeltec 1030-Autoanalyser (Tecator AB, Höganäs, Sweden), by the 3'5-dinitro-salicylic acid method ( $\mathrm{Yu}$ et al. 1998) and by combustion at $550^{\circ} \mathrm{C}$ for $16 \mathrm{~h}$, respectively. Because each experimental group was distributed into three tanks and that fish captured from the same tank were pooled, there were only three values for a whole group (n 3).

\section{Total lipid and fatty acid analysis}

Total lipids of muscle, liver and mesenteric fat were extracted according to Bligh \& Dyer (1959). Fatty acids from lipid samples were methylated using $10 \%$ potassium hydroxide in methanol for $1 \mathrm{~h}$ at room temperature (Zheng et al. 2002). Fatty acid methyl esters were then analysed and quantified using a Hewlett-Packard HP-5890 gas chromatograph (Hewlett-Packard, Avondale, PA, USA) in a cross-linked $5 \%$ phenylmethyl silicone gum phase column (length $25 \mathrm{~m}$; internal diameter $0.32 \mathrm{~mm}$; film thickness $0.25 \mu \mathrm{m} ; \mathrm{N}_{2}$ as the carrier gas; HP-Ultra 2), equipped with flame ionisation detection. The injector and detector temperatures were 280 and $300^{\circ} \mathrm{C}$, respectively. The column temperature set at $190^{\circ} \mathrm{C}$ was then 
Table 2. Growth-related parameters and slaughter variables of juvenile grass carp (Ctenopharyngodon idella) fed diets containing three different lipid levels

(Mean values with their standard errors ( $n$ 3; one value per tank))

\begin{tabular}{|c|c|c|c|c|c|c|}
\hline & \multicolumn{6}{|c|}{ Experimental diets } \\
\hline & \multicolumn{2}{|c|}{ L2 } & \multicolumn{2}{|c|}{ L6 } & \multicolumn{2}{|c|}{ L10 } \\
\hline & Mean & SEM & Mean & SEM & Mean & SEM \\
\hline Feed intake (g/fish)* & $14 \cdot 2$ & 0.3 & $14 \cdot 3$ & 0.2 & $12 \cdot 2$ & $1 \cdot 0$ \\
\hline Lipid intake (g/fish)* & $0 \cdot 24^{a}$ & 0.01 & $0.75^{\mathrm{b}}$ & 0.01 & $1.05^{c}$ & 0.01 \\
\hline Weight gain $†$ & $206 \cdot 5^{b}$ & $5 \cdot 8$ & $201 \cdot 2^{b}$ & $3 \cdot 5$ & $164 \cdot 8$ & $10 \cdot 5$ \\
\hline Feed efficiency§ & $0.59^{b}$ & 0.01 & $0.57^{a, b}$ & 0.01 & $0.55^{a}$ & 0.01 \\
\hline Protein efficiency\|l & $1 \cdot 87$ & 0.04 & $1 \cdot 81$ & 0.03 & $1 \cdot 76$ & 0.03 \\
\hline Protein retention & $27 \cdot 4$ & 0.8 & $25 \cdot 8$ & 0.4 & $23 \cdot 4$ & $1 \cdot 7$ \\
\hline Lipid retention** & $284 \cdot 6^{c}$ & 3.9 & $122 \cdot 9^{b}$ & $1 \cdot 0$ & $83 \cdot 1^{a}$ & 4.4 \\
\hline Condition factor†† & 2.08 & 0.02 & $2 \cdot 19$ & 0.06 & 2.09 & 0.06 \\
\hline Viscera index㧊 & $10 \cdot 02^{\mathrm{a}}$ & 0.20 & $10 \cdot 91^{a, b}$ & 0.24 & $11 \cdot 91^{\mathrm{b}}$ & 0.45 \\
\hline Hepatosomatic index§§ & 2.50 & 0.15 & $2 \cdot 72$ & $0 \cdot 16$ & $2 \cdot 85$ & $0 \cdot 16$ \\
\hline Mesenteric fat index\| \| & $1.64^{\mathrm{a}}$ & 0.19 & $2 \cdot 45^{b}$ & 0.14 & $2 \cdot 81^{b}$ & 0.20 \\
\hline
\end{tabular}

a,b,c Mean values within a row with unlike superscript letters were significantly different $(P<0.05)$.

*Values are given for the whole experiment $(56 \mathrm{~d})$.

$\dagger$ Weight gain $=($ final weight - initial weight $) \times 100 /$ (initial weight $)$.

$\neq$ Specific growth rate $=($ In final weight $-\ln$ initial weight $) \times 100 /$ d.

$\S$ Feed efficiency $=$ (fish weight gain) $/($ feed intake $)$.

$\|$ Protein efficiency $=($ final weight - initial weight $) \times 100 /($ protein intake $)$.

I Protein retention $=$ (fish protein gain $) \times 100 /($ protein intake $)$

${ }^{* *}$ Lipid retention $=($ fish lipid gain $) \times 100 /$ (lipid intake $)$

t† Condition factor $=$ fish weight $(\mathrm{g}) \times 100 /$ body length $^{3}(\mathrm{~cm})$.

拉 Viscera index $=$ viscera weight $\times 100 /$ fish weight.

$\S \S$ Hepatosomatic index $=$ liver weight $\times 100 /$ fish weight

|| || Mesenteric fat index $=$ mesenteric fat weight $\times 100 /$ fish weight

increased to $260^{\circ} \mathrm{C}\left(2^{\circ} \mathrm{C} / \mathrm{min}\right)$ and held for $5 \mathrm{~min}$. Results are expressed as the percentage of each fatty acid with respect to total fatty acids.

\section{Plasma analysis}

Blood was collected with a heparinised microsyringe from the hearts of five $24 \mathrm{~h}$-fasted fish taken from each tank and was immediately centrifuged. Plasma samples were frozen at $-26^{\circ} \mathrm{C}$ until analysis. Plasma total triacylglycerols, cholesterol, HDL-cholesterol and LDL-cholesterol were assayed by enzymic procedures using an automatic biochemical analyser (Hitachi 7170; Hitachi, Tokyo, Japan) and attached kits (Daiichi Pure Chemicals Co., Tokyo, Japan). Triacylglycerol was measured after lipase hydrolysis by the glycerol phosphate oxidase-peroxidase-amidopyrine method (Jacobs \& Vandemark, 1960; Koditschek \& Umbreit, 1969), and cholesterol by the cholesterol oxidase-peroxidase-amidopyrine method (Richmond, 1973; Roeschlau et al. 1974). For lipoproteins, HDL or LDL were selected by specific detergent-dependent disruption and elimination of other lipoproteins (Good's buffer solution; Daiichi Pure Chemicals Co., Tokyo, Japan). Then cholesterol released by cholesterol esterase from either of the selected lipoproteins and treated with cholesterol oxidase produced $\mathrm{H}_{2} \mathrm{O}_{2}$. The amount of $\mathrm{H}_{2} \mathrm{O}_{2}$ that is proportional to the amount of cholesterol was measured colorimetrically in the presence of 4-aminoantipyrine and N,N,-bis (4-sulfobutyl)-m-toluidine (Gordon et al. 1977; Bachorik \& Ross, 1995; Nakamura et al. 1997; Arranz-Pena et al. 1998). Thiobarbituric acid-reactive substances were estimated as described by Rueda-Jasso et al. (2004) using a malondialdehyde kit (Jiancheng Biotech Co., Nanjing, China).

\section{Palmitate oxidation by mitochondria and peroxisomes of liver homogenates}

Pieces of liver were homogenised in 20 vol. of chilled $0 \cdot 25 \mathrm{M}$ sucrose containing $2 \mathrm{~mm}$-ethylene-glycol-bis(a-aminoethyl)$\mathrm{N}, \mathrm{N}, \mathrm{N}^{\prime}, \mathrm{N}^{\prime}$-tetra-acetic acid and $10 \mathrm{~mm}$-tri(hydroxymethyl)aminomethane- $\mathrm{HCl}$, pH 7.4, using a Teflon pestle in a cooled Potter-Elvehjem homogeniser (Wheaton Science Products, Millville, NJ, USA). Palmitate oxidation rates were measured at $37^{\circ} \mathrm{C}$ using two media as described by Veerkamp et al. (1983), the first allowing the mitochondrial and peroxisomal activities to occur $(30 \mathrm{~mm}-\mathrm{KCl}, 75 \mathrm{~mm}$-tri(hydroxymethyl)-aminomethane- $\mathrm{HCl}, \quad \mathrm{pH} \quad 7 \cdot 4, \quad 10 \mathrm{~mm}$-potassium phosphate buffer, $0.7 \mathrm{~mm}$-ethylene-glycol-bis(a-aminoethyl)$\mathrm{N}, \mathrm{N}, \mathrm{N}^{\prime}, \mathrm{N}^{\prime}$-tetra-acetic acid, $5 \mathrm{~mm}-\mathrm{MgCl}_{2}, 1 \mathrm{~mm}-\mathrm{NAD}, 5 \mathrm{~mm}-$ ATP, $100 \mu \mathrm{M}$-CoA, $0.4 \mathrm{mM}$-L-carnitine, $0.5 \mathrm{~mm}-\mathrm{L}$-malate, and $25 \mu \mathrm{M}$-cytochrome $\mathrm{c}$ ), the second allowing the peroxisomal activity only (the medium only differing by the absence of L-malate, cytochrome c, and L-carnitine, and the presence of $73 \mu \mathrm{M}$-antimycin and $10 \mu \mathrm{M}$-rotenone to block the respiratory chain). After $30 \mathrm{~min}$, the radioactivity initially held by $\left[1-{ }^{14} \mathrm{C}\right]$ palmitate (bound to bovine serum albumin in a $5: 1$ molar ratio) was recovered on short labelled molecules released from the $\beta$-oxidative cycle and soluble in perchloric acid (acid-soluble products). The radioactivity of $1 \mathrm{ml}$ of acidsoluble products was measured after mixing with $6 \mathrm{ml}$ of a liquid scintillation cocktail containing 2,5-diphenyloxazole $(0.58 \%)$, 1,4-bis (5-phenyloxazole-2-yl) benzene (0.18\%), 
benzene $(9.85 \%)$ and 1,4-dioxane $(89.55 \%)$ as described by Chen et al. (1992) in a liquid scintillation spectrometer (LS3500; Beckman Coulter Inc., Fullerton, CA, USA).

\section{Isolation of mitochondrial fractions}

Pieces of liver (about $3 \mathrm{~g}$ ) from seven to nine fish of every tank (three tanks per experimental treatment) were collected and cut finely in ice-cold $0 \cdot 25 \mathrm{M}$-sucrose medium containing $1 \mathrm{~mm}$ ethylene-glycol-bis(a-aminoethyl)-N, $\mathrm{N}, \mathrm{N}^{\prime}, \mathrm{N}^{\prime}$-tetra-acetic acid

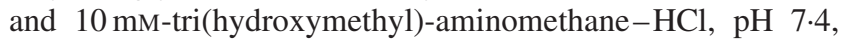
rinsed five times in the same medium, blotted with absorbent paper and weighed. The tissue was diluted $(1: 10, \mathrm{w} / \mathrm{v})$ in the chilled sucrose medium containing $10 \%$ fatty-acid-free albumin, and homogenised using the PotterElvehjem homogeniser as described earlier. The homogenate was centrifuged at $2500 \mathrm{~g}$ for $4 \mathrm{~min}$ at $4^{\circ} \mathrm{C}$ and the supernatant fraction was immediately centrifuged at $16000 \mathrm{~g}$ for $6 \mathrm{~min}$ in a centrifuge (Avanti J-20 XPI; Beckman). The pellet obtained from the second centrifugation was re-suspended with the sucrose medium without albumin and centrifuged under the preceding conditions. The procedure was repeated once. The pellet resulting from the last centrifugation and re-suspended in buffered $0.3 \mathrm{M}$-sucrose was used as the mitochondrial fraction. The protein content of this fraction was roughly estimated by spectrophotometry (Clouet et al. 1989) for immediate measurements, but was determined later more precisely with the bicinchoninic acid procedure (Smith et al. 1985).

\section{Palmitate oxidation by isolated mitochondria}

Isolated mitochondria were used to assess whether activity rates previously measured in liver homogenates and related to mitochondria resulted from activity actually altered within mitochondria or from interferences with other reactions (for example, common use of acyl-CoA for peroxisomal fatty acid oxidation and microsomal esterification). The activity of carnitine palmitoyltransferase I, the key enzyme of the mitochondrial fatty acid oxidation, was measured in the presence of freshly isolated mitochondria using ${ }^{3} \mathrm{H}$-labelled L-carnitine with palmitoyl-CoA, and extraction of the palmitoyl- $\left[{ }^{3} \mathrm{H}\right]$ carnitine produced using butan- $1-\mathrm{ol}$, according to the general procedure described by Bremer (1981). The associated radioactivity was counted, after mixing with the scintillation cocktail described earlier (Chen et al. 1992). Palmitate oxidation rates were also measured in the presence of freshly isolated liver mitochondria in a medium containing $\left[1-{ }^{14} \mathrm{C}\right]$ palmitate (bound to bovine serum albumin in a $1 \cdot 5: 1$ molar ratio). The reaction was stopped after $8 \mathrm{~min}$ with perchloric acid according to the procedure of Clouet et al. (1989). The radioactivity of acid-soluble products was measured as above for the palmitate oxidation by liver homogenates.

\section{Mitochondrial and peroxisomal marker enzymes}

The presence of mitochondria was assessed by the activity of monoamine oxidase as demonstrated by Weissbach et al. (1960). The mitochondrial protein content per g liver is calculated by dividing the activity of monoamine oxidase per g liver by the activity expressed per mg mitochondrial protein. The presence of peroxisomes was assessed by the activity of catalase measured using the procedure described by Aebi (1974).

\section{Microscopy procedure}

At the end of the experiment, pieces of liver of fish fed the three experimental diets (nine fish per diet) were fixed in $10 \%$ formaldehyde and embedded in paraffin. Sections of $5 \mu \mathrm{m}$ thickness were stained with haematoxylin-eosin and examined under a light microscope as described by Bancroft \& Stevens (1977).

\section{Statistical analysis}

The data are expressed as mean values with their standard errors ( $n 3$; one value per tank). The data of the different treatments were submitted to one-way ANOVA. When a significant difference was found at $P<0 \cdot 05$, Duncan's multiple range test was used to estimate the difference. All analyses were made using SPSS 9.0 software (SPSS Inc., Chicago, IL, USA).

\section{Results \\ Feeding and growth parameters}

Mortality at the end of the experiment was low (about $5 \%$ ) and unrelated to experimental treatments. The behaviour of fish was observed every day during the whole experimental period. According to the quantification of food intake corrected from food wasted and visual observation, it appears that, over the whole trial period, all fish from the L2 and L6 groups ingested the same amount of food. Meanwhile, fish from the L10 group had a marked tendency to eat less, this being associated with significant $P$ lesser weight gain and specific growth rate. This poor appetite could be also recognised by the fact that most fish of the L10 group needed about twofold more time to eat up their ration than those of the other two groups, some of them even stopping eating in the last $3 \mathrm{~d}$ of the experimental period. As shown in Table 2 , there was no significant difference in growth parameters, feed efficiency and protein retention between the L2 and L6 groups, but the lipid retention was significantly lower in the L6 group. With the L10 diet, there was only a tendency to a decrease in protein retention. In this latter group, there was also a very significant decrease in lipid retention $(P<0 \cdot 001)$, as compared with the other two groups, despite the increase in lipid intake (Table 2). Some slaughter indices also presented in Table 2 indicate that there was no significant difference in condition factor between all the experimental groups. Viscera index increased with the increase in dietary fat levels, but significantly only between the L2 and L10 groups. MFI also significantly increased with the increase in dietary fat levels, but without significant difference between the L6 and L10 groups. Although the hepatosomatic index did not show any significant difference between the groups, a tendency similar to that of viscera index and MFI was apparent. 


\section{Body composition and plasma parameters}

No significant differences were found for whole-body moisture, protein or ash contents of fish fed the diets with increasing lipid levels (Table 3 ). Whole-body lipid levels were not different between the L6 and L10 groups, but were significantly greater than that in the L2 group. Similar observations were found in both muscle $(P<0.05)$ and liver, although not significantly for liver (see Table 4). Plasma parameters reported in Table 3 show that triacylglycerol, cholesterol and LDLcholesterol concentrations significantly increased with the increase in dietary lipid level at $P<0 \cdot 05$, but with no significant differences being noted between the L2 and L6 groups for cholesterol or LDL-cholesterol. As for HDL-cholesterol, only a non-significant trend of increasing concentration with a rise in lipid level was noticed. As regards the thiobarbituric acidreactive substances measured in blood, their concentrations were found to significantly increase with the increase in dietary lipid level at $P<0 \cdot 05$.

\section{Tissue fatty acid composition}

The fatty acid compositions of muscle, liver and mesenteric fat tissue are given in Table 4. With increasing dietary lipid levels, the composition of practically all fatty acid families significantly differed in lipids of each organ and also between the three organs. Saturated fatty acids and MUFA were significantly decreased in the mesenteric fat tissue, while saturated fatty acids were increased in liver lipids at $P<0 \cdot 05$, when the dietary lipid levels were increased. MUFA accumulated more particularly within lipids of mesenteric fat tissue, with about $50 \%$ of oleic acid. In the muscle, MUFA were strongly reduced, while $n-6$ and $n$-3 PUFA accumulated. These specificities were significantly accentuated with the increase in dietary lipid level (see Table 4). As regards the individual fatty acid profiles, the number of fatty acids affected by the lipid content of diets was greater in mesenteric fat tissue than in muscle, and was relatively low in liver. It was also worth noting that the composition of some $n-6$ and $n-3$ PUFA was significantly altered only in the mesenteric fat tissue $(18: 2 n-6,20: 2 n-6,20: 3 n-6,22: 5 n-3$,
$22: 5 n-6)$. The composition of $n-3$ PUFA mainly represented by DHA was significantly increased in lipids of the three organs studied with the increase in dietary lipid level.

\section{Hepatic histology study}

The surface of livers in the L2 group was uniformly red as well as most of the surface of livers of the L6 and L10 groups, but in these latter groups there were some 'creamy' areas as islands in the middle of the red surface. The total surface of these islands in the L10 group was greater than in the L6 group, but the internal part of liver in the L6 and L10 groups was totally normal. When these islands were finely dissected from the surface of any livers of the L6 or L10 group and stained, hepatocytes appeared to be hypertrophied with white internal spaces (data not shown), probably previously full of fat droplets that were washed away by the organic solvents used during the preparation of the histological samples. This contrasted with the normal size and content of cells from tissues sampled on the normal red part of liver from all the groups.

\section{Hepatic fatty acid oxidation}

As regards mitochondria, from monoamine oxidase activity rates measured in liver homogenates and mitochondrial fractions, the calculated mitochondrial protein content per $g$ liver was found to significantly decrease with the increase in dietary lipid level. For the parameters related to mitochondrial fatty acid oxidation, palmitate oxidation rates measured using liver homogenates decreased with increasing dietary lipid level (Table 5). When expressed per mg protein of mitochondrial fractions, palmitate oxidation rates were similar in the L2 and L6 groups, but were significantly lower in the L10 group. Concerning carnitine palmitoyltransferase I, its activity rates per mg protein of mitochondrial fractions were relatively similar in the three groups (Table 5). As regards peroxisomes, catalase activity rates were shown to significantly decrease with the increase in dietary lipid level. Peroxisomal palmitate oxidation rates expressed per $g$ of liver homogenates were similar

Table 3. Body composition, plasma lipid parameters and thiobarbituric acid-reactive substances (TBARS) in grass carp (Ctenopharyngodon idella) fed diets containing different lipid levels

(Mean values with their standard errors ( $n$ 3; one value per tank))

\begin{tabular}{|c|c|c|c|c|c|c|c|c|}
\hline & & & \multicolumn{6}{|c|}{ Experimental diets } \\
\hline & \multicolumn{2}{|c|}{ Initial composition } & \multicolumn{2}{|c|}{ L2 } & \multicolumn{2}{|c|}{ L6 } & \multicolumn{2}{|c|}{ L10 } \\
\hline & Mean & SEM & Mean & SEM & Mean & SEM & Mean & SEM \\
\hline \multicolumn{9}{|l|}{ Body composition (\%) } \\
\hline Moisture & $81 \cdot 6$ & 0.4 & $76 \cdot 5$ & $0 \cdot 1$ & $74 \cdot 3$ & 0.2 & $74 \cdot 3$ & $1 \cdot 3$ \\
\hline Protein & $14 \cdot 0$ & $0 \cdot 1$ & $14 \cdot 5$ & 0.2 & $14 \cdot 2$ & $0 \cdot 1$ & $13 \cdot 6$ & $0 \cdot 6$ \\
\hline Lipid & 0.76 & 0.08 & $5 \cdot 85^{\mathrm{a}}$ & 0.03 & $7 \cdot 74^{b}$ & $0 \cdot 13$ & $8.47^{b}$ & 0.47 \\
\hline Ash & 2.65 & 0.04 & 2.54 & 0.01 & $2 \cdot 51$ & 0.05 & 2.57 & 0.08 \\
\hline \multicolumn{9}{|l|}{ Plasma index (mM) } \\
\hline Triacylglycerol & & & $1.93^{\mathrm{a}}$ & 0.05 & $2 \cdot 47^{b}$ & 0.06 & $2 \cdot 85^{\mathrm{c}}$ & $0 \cdot 11$ \\
\hline Cholesterol & & & $2 \cdot 82^{\mathrm{a}}$ & 0.11 & $3.41^{\mathrm{a}}$ & 0.27 & $5 \cdot 10^{\mathrm{b}}$ & 0.28 \\
\hline HDL-cholesterol & & & 0.38 & 0.07 & 0.35 & 0.04 & 0.42 & 0.08 \\
\hline LDL-cholesterol & & & $0 \cdot 21^{\mathrm{a}}$ & 0.04 & $0.28^{\mathrm{a}}$ & 0.06 & $0.45^{\mathrm{b}}$ & 0.08 \\
\hline Plasma TBARS (nM) & & & $1.55^{\mathrm{a}}$ & $0 \cdot 13$ & $3 \cdot 37^{b}$ & 0.46 & $5 \cdot 40^{\mathrm{C}}$ & 0.63 \\
\hline
\end{tabular}

a,b,c Mean values within a row with unlike superscript letters were significantly different $(P<0.05)$. 


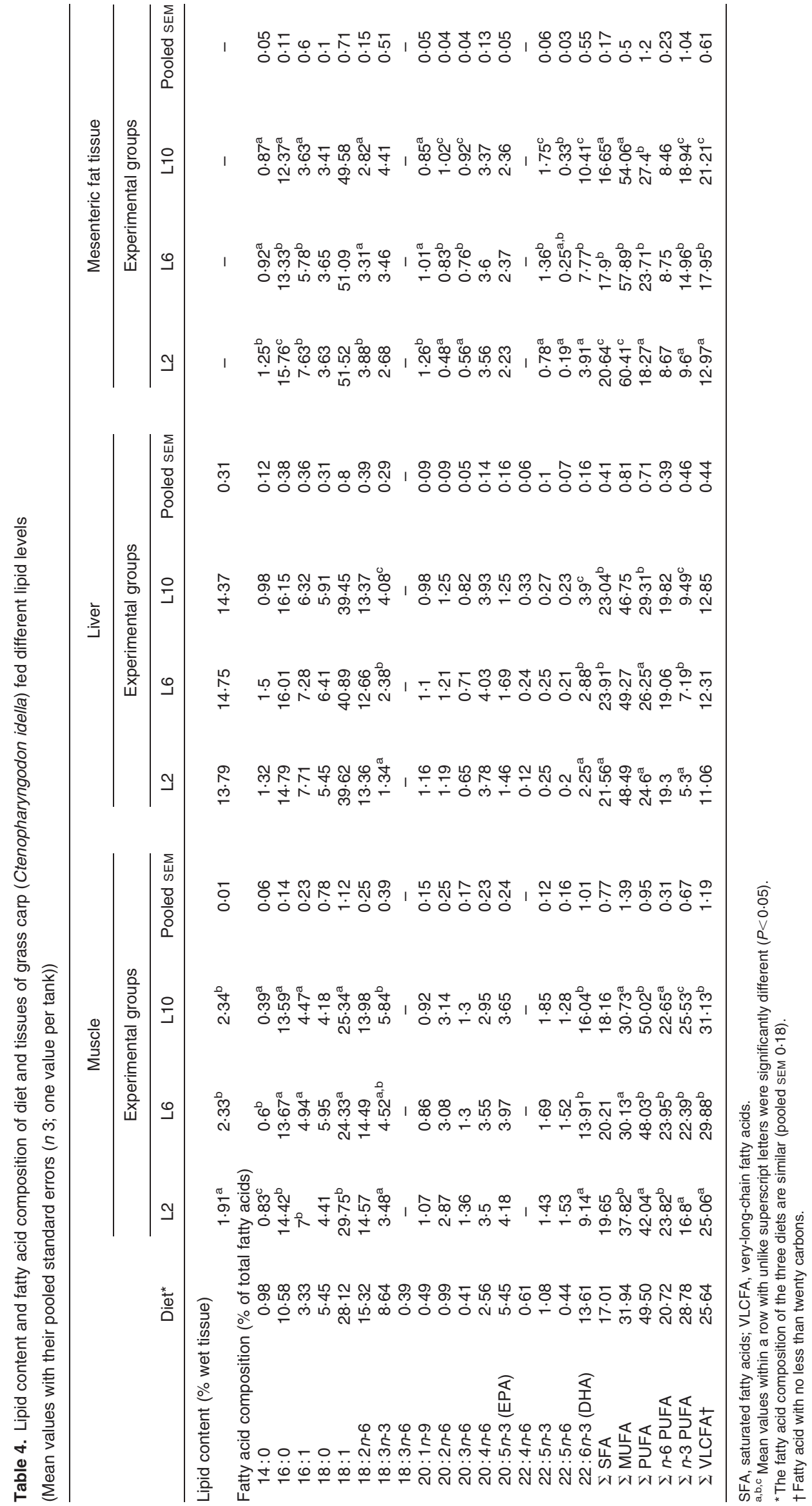


Table 5. Effects of diets containing different lipid levels on parameters related to mitochondrial and peroxisomal activities in the liver of grass carp (Ctenopharyngodon idella)

(Mean values with their standard errors)

\begin{tabular}{|c|c|c|c|c|c|c|}
\hline & \multicolumn{6}{|c|}{ Experimental diets } \\
\hline & \multicolumn{2}{|c|}{ L2 } & \multicolumn{2}{|c|}{ L6 } & \multicolumn{2}{|c|}{ L10 } \\
\hline & Mean & SEM & Mean & SEM & Mean & SEM \\
\hline \multicolumn{7}{|l|}{ Mitochondrial parameters } \\
\hline \multicolumn{7}{|l|}{ Monoamine oxidase activity } \\
\hline In tissue homogenates (mIU/g wet tissue) & $46 \cdot 1^{\mathrm{c}}$ & 1.0 & $40 \cdot 7^{b}$ & 0.5 & $30 \cdot 8^{a}$ & $1 \cdot 2$ \\
\hline In mitochondrial fractions (mlU/mg protein) & $6 \cdot 3^{\mathrm{a}}$ & 0.1 & $6 \cdot 7^{\mathrm{a}}$ & 0.3 & $8 \cdot 1^{\mathrm{b}}$ & 0.3 \\
\hline Mitochondrial protein content (mg protein/g wet tissue) & $7 \cdot 3^{\mathrm{c}}$ & 0.1 & $6 \cdot 1^{\mathrm{b}}$ & 0.2 & $3 \cdot 8^{\mathrm{a}}$ & $0 \cdot 1$ \\
\hline \multicolumn{7}{|l|}{ Carnitine-dependent palmitate oxidation } \\
\hline In tissue homogenates (nmol/min per g wet liver) & $97 \cdot 6^{\mathrm{c}}$ & 2.5 & $84 \cdot 1^{\mathrm{b}}$ & $1 \cdot 7$ & $74 \cdot 7^{\mathrm{a}}$ & $2 \cdot 2$ \\
\hline In mitochondrial fractions (nmol/min per mg protein) & $0 \cdot 16^{\mathrm{b}}$ & 0.01 & $0 \cdot 17^{\mathrm{b}}$ & 0.01 & $0 \cdot 12^{\mathrm{a}}$ & 0.01 \\
\hline \multicolumn{7}{|l|}{ Carnitine palmitoyltransferase I } \\
\hline In mitochondrial fractions (nmol/min per mg protein) & $3 \cdot 8$ & 0.2 & 3.6 & $0 \cdot 2$ & 3.6 & 0.2 \\
\hline \multicolumn{7}{|l|}{ Peroxisomal parameters } \\
\hline Catalase activity $\left(\mathrm{IU} \times 10^{3} / \mathrm{g}\right.$ wet tissue $)$ & $59 \cdot 2^{\mathrm{C}}$ & $1 \cdot 8$ & $53 \cdot 6^{b}$ & 1.5 & $46 \cdot 9^{a}$ & $1 \cdot 8$ \\
\hline $\begin{array}{l}\text { Carnitine-independent palmitate oxidation in tissue homogenates } \\
\text { (nmol/min per g wet liver) }\end{array}$ & $11 \cdot 8^{\mathrm{b}}$ & $11 \cdot 8$ & $11.9^{b}$ & 0.2 & $9 \cdot 2^{a}$ & 0.3 \\
\hline
\end{tabular}

a,b,c Mean values within a row with unlike superscript letters were significantly different $(P<0.05)$.

in the L2 and L6 groups, but were significantly lower in the L10 group (Table 5).

\section{Discussion}

\section{Growth v. dietary lipid and protein-sparing effect}

The increase in dietary energy level has been reported to exert a protein-sparing effect in most aquaculture fish species (Watanabe, 1982; Beamish \& Medland, 1986; Cho \& Kaushik, 1990; Dias et al. 1998), but nothing comparable was observed with grass carp fed the L2, L6 or L10 diets. The slightly depressed protein retention when the dietary lipid levels increased from 2 to $10 \%$ would even suggest that protein was used for energy production. From experiments performed on carp fed a dietary lipid level of $15 \%$, Takeuchi et al. (1979) observed no negative or positive effect on growth, which strongly suggests that the lipid mixture containing EPA-rich Pollock oil was much less harmful than that used by ourselves containing two times more DHA than EPA. The comparison of both experiments tends to point out that DHA was potentially responsible for the damages occurring in the L10 group (decreased growth, blood lipid peroxidation). The decreased food intake should be an additional cause of the lower growth performance indexes met in the L10 group, as it has been reported in turbot (Cacerez-Martinez et al. 1984; Regost et al. 2001), salmon (Silverstein et al. 1999), rainbow trout (Weatherup et al. 1997) and carp (Murai et al. 1985). Generally, fish (Cho \& Kaushik, 1985; Kaushik \& Medale, 1994) as well as homeothermal animals (Kissileff \& van Itallie, 1982) are assumed to adjust their feed intake on their strict energy requirements, but this does not seem to apply to grass carp because, in the present study, feed intakes were not statistically different between the three experimental groups. Former studies (Du et al. 2005) have also shown that there was a dietary energy limit within which grass carp preferentially adjusted intake to protein before energy, and conversely reduced feed intake to avoid excessive energy intake when dietary energy exceeded the limit.

\section{Lipid deposition}

With the increase in dietary lipid level, the significant decrease in lipid retention could suggest that an increased proportion of lipid was used as a source of energy, which would be in agreement with experiments performed with rainbow trout and European sea bass (Peres \& Oliva-Teles, 1999b). However, decreased lipid retention could also result from lower food intake. Anorexia symptoms met only in the L10 group might represent a behavioural answer when the hypothalamic centre for satiety is excessively stimulated by anorexigen compounds, as some of them, such as leptin, are more abundantly released from fat-repleted adipose tissues (Schwartz et al. 1999). Nevertheless, this hypothesis appears unsatisfactory with the L6 and L10 groups because their MFI and body lipid composition were statistically comparable, with anorexia symptoms occurring only in the L10 group. In fact, the markedly decreased lipid retention in the L10 group was probably due to the overestimated lipid intake value calculated from gross food intake and corresponding lipid content $(10 \%)$, but which did not take into account a very possible greater loss of dietary lipids through faeces. If lipid intake were calculated from the difference between input and actual output of lipids, its values would be then much lower, resulting in more elevated lipid retention values. Indeed, cases of reduced lipid digestibility in fish fed excess dietary lipid levels have been reported in rainbow trout (Austreng, 1979), cod (Lie et al. 1988) and Atlantic halibut (Berge \& Storebakken, 1991). One can admit that lipid retention is not a totally valuable parameter under aquatic conditions, depending on fish species and diet composition. The discrepancy between low calculated lipid intake with high lipid retention in the L2 group and high calculated lipid intake with low lipid retention in the L10 group, with an intermediary situation in the L6 group, prompts us to suggest that lipid digestibility and absorption decreased with the increase in dietary lipid level. In the L6 and L10 groups, the lowered hepatic fatty acid oxidation (Table 5), which should result in the accumulation of 
non-oxidised fatty acids, may amplify the consequence of the increased dietary lipid level, as suggested by the significant increase in MFI and the tendency of the hepatosomatic index to increase. These data agree with those obtained from other fish species (Martino et al. 2002).

\section{Liver metabolic status}

Despite the different lipid levels in the L6 and L10 diets, the liver lipid contents of the three groups were similar $(<15 \%)$. These data were, however, associated with markedly greater plasma triacylglycerol contents in the L6 and L10 groups. The progressive enrichment of plasma in lipoproteins (and constitutive triacylglycerol and cholesterol) from L2 to L10 groups strongly suggested that the liver capacities to synthesise and secrete lipoproteins in grass carp were adapted to all the various levels of dietary lipids. Although clusters of swollen hepatocytes full of fat droplets were observed on the liver surfaces of the L6 and L10 groups, they represented very small volumes compared with the much larger normal part of liver, which could not alter the tissue lipid contents (Table 4). However, swollen hepatocytes were probably very early signs of future fatty liver symptoms, as has already been reported (Lin et al. 1990).

\section{Tissue fatty acid composition}

One interest of the study was to show that the dietary lipid level affected, not only qualitatively (between the different fatty acids in the same group), but also quantitatively (for the same fatty acids between the three groups) the fatty acid composition of the three tissues investigated. According to the amount of each fatty acid recovered per tissue in each group, fatty acid composition significantly differed with dietary lipid level for two fatty acids in liver $(\alpha$-linolenic acid and DHA), for six fatty acids in muscle and ten fatty acids in mesenteric fat tissue. As previously reported (Bilinski \& Jonas, 1970; Henderson \& Tocher, 1987; Henderson, 1996; Frøyland et al. 2000), liver was considered to be much more active for fatty acid metabolism than muscle in fish. Also in the present study, the relatively strict steady state of fatty acid composition in the liver with the three diets should be attributed to the active lipid metabolism of this organ. This implies that the composition of each fatty acid was maintained through several adaptive regulation mechanisms despite increase or decrease in dietary lipid level. It has been shown that liver lipogenesis capacities increased when fish were fed low-fat diets or decreased when fed high-fat diets (Pullman et al. 1990; Gaye-Siessegger et al. 2004; Wang et al. 2005). The fatty acid composition of liver could also be altered by the rate of lipoprotein secretion that seemed to increase with dietary lipid level in the present study. However, these regulation mechanisms do not seem to involve $\alpha$-linolenic acid and DHA, whose compositions increased with the increase in dietary lipid level. It was surprising that DHA was at a much lower percentage in liver than in muscle and mesenteric fat tissue. Given the major role of DHA in membrane phospholipids, the present data strongly suggest that DHA was exported through hepatic lipoprotein secretion to tissues rich in membranes, but also slightly accumulated in liver with the increase in dietary lipid level. $\alpha$-Linolenic acid was reported to be preferentially oxidised and to be also incorporated into triacylglycerols and membrane phospholipids as well, but to a lesser extent than DHA (Demar et al. 2005). Through its membrane incorporation, $\alpha$-linolenic acid would follow the fate of DHA and would be similarly affected by dietary lipid level. In mesenteric fat tissue, ten fatty acids were differently and significantly affected by the increase in dietary lipid level, which means that the regulation mechanisms in this tissue would be much less active than in the liver. As a growing storage organ (see MFI in Table 2), mesenteric fat tissue is expected to retain a range of fatty acids all originating from dietary lipids, from blood lipoproteins and from its own lipogenesis for its triacylglycerol synthesis and membrane phospholipid formation. With the increase in dietary lipid level, fatty acids should accumulate if they were trapped for membrane phospholipid formation (as DHA and some other very-long-chain fatty acids with twenty carbons), or should decrease if they were more easily released through triacylglycerol hydrolysis (as palmitic and palmitoleic acids). As the lipogenic pathway was reported to be repressed in fish by increased fatty acid cellular level (Gaye-Siessegger et al. 2004), a reduced fatty acid synthesis due to increased dietary lipid level should also explain the decrease in palmitic and palmitoleic acids as first products of lipogenesis. In muscle, six fatty acids were differently affected when the dietary lipid level increased from 2 to $10 \%$, which was relatively close to the number found for the mesenteric fat tissue. However, lipid composition of muscle appeared to be very rich in PUFA ( $42-50 \%$ of total fatty acids) compared with mesenteric fat tissue (18-27\%) and liver (24-29\%). This should be related to the very high membrane content of muscle cells for which the requirement in PUFA for phospholipid formation is elevated. As some studies reported that muscle PUFA contents increased when fish were fed diets containing fish oil (Xu et al. 1993; Bell et al. 2001; Nanton et al. 2003), our data obtained in grass carp indicate that increasing ingestion of lipids containing PUFA could be responsible for the increasing accumulation of PUFA in muscle. The decreased percentages of other fatty acids observed in the present study with the increase in dietary lipid level should be not only due to the dramatically increased percentages of PUFA in muscle, but also to the usually better oxidation of these fatty acids in mitochondria isolated from fish muscle (Murata \& Higashi, 1979).

\section{Hepatic fatty acid oxidation}

In addition to hepatic lipoprotein secretion and lipogenesis, fatty acid oxidation may also be of some importance in the regulation of liver lipid metabolism, especially when animals ingest high-fat diets. In the present study, $\alpha$-linolenic acid and DHA accumulated in the three organs studied with the increase in dietary lipid level. Even if this should be largely explained by the requirement for phospholipid formation, fatty acid oxidation pathways should represent parts of adaptive regulation mechanisms involved in the steady state of fatty acid composition. In mammals, long-chain fatty acids from sixteen to eighteen carbons are mainly oxidised within mitochondria (Mannaerts et al. 1979). Among them, $\alpha$-linolenic acid was demonstrated to be one of the best substrates for the whole mitochondrial oxidation pathway through the key 
step represented by carnitine palmitoyltransferase I (Clouet et al. 1989; Gavino \& Gavino, 1991). These data show that, in grass carp, the decrease in mitochondrial fatty acid oxidation rates per $g$ liver with the increase in dietary lipid level was not due to lower carnitine palmitoyltransferase I activity rate per mg mitochondrial protein, but to the particularly dramatic decrease in mitochondrial protein content per $\mathrm{g}$ liver. The whole decrease in mitochondrial fatty acid oxidation should evenly affect all fatty acids of liver lipids, but among them, only $\alpha$-linolenic acid was shown to accumulate with the increase in dietary lipid level. This suggested that $\alpha$-linolenic acid was used more actively for phospholipid synthesis and lipoprotein formation than were the other fatty acids from sixteen to eighteen carbons. As the main very-long-chain fatty acid of the diet, DHA is reported to be essentially oxidised within peroxisomes in mammals (Hagve \& Christophersen, 1986; Madsen et al. 1998), the same conclusion should be indirectly held in fish because DHA was shown to be a very poor substrate for mitochondrial fatty acid oxidation, as compared with oleic acid, in eel, tilapia, trout and seabream (Murata, 1979). However, the proportion of DHA in hepatic lipids ( $2-4 \%$ of total fatty acids) was clearly lower than in muscle $(9-16 \%)$ and mesenteric fat tissue $(4-10 \%)$, which suggests that DHA was largely removed from liver through lipoprotein secretion. As peroxisomal fatty acid oxidation rates were greater in liver than in muscle of haddock (Nanton et al. 2003) and Atlantic salmon (Frøyland et al. 2000), it may be thought that hepatic DHA could be reduced through peroxisomal fatty acid oxidation. Yet, despite the similar fatty acid oxidation rates in the L2 and the L6 groups (Table 5), the DHA composition was significantly greater in the L6 group than in the L2 group. This suggests that, in spite of a likely increased lipoprotein secretion, the increased percentage of DHA in the L6 group was actually due to mechanisms related to phospholipid formation. This effect could be strengthened in the L10 group in which peroxisomal fatty acid oxidation rates were about $20 \%$ lower than in the L2 and L6 groups. The accumulation of DHA in the liver of grass carp, which was associated with a weak increase in peroxisomal fatty acid oxidation activity, appears surprising since, in mammals, fish oil and constitutive DHA were considered to increase hepatic fatty acid oxidation (Vamecq et al. 1993; van den Branden et al. 1995; Hong et al. 2003) through the activation of PPAR- $\alpha$ (Latruffe \& Vamecq, 1997; Ren et al. 1997). Consequently, it is likely that DHA could not exert any favourable effects on hepatic fatty acid oxidation in grass carp. One explanation is that most nuclear receptors are not or only few are sensitive to the activation usually exerted in mammals by very-long-chain fatty acids (Forman et al. 1997), and in fish the sensitivity of PPAR to clofibric acid and PUFA was shown to be clearly lower than in other animals (Ruyter et al. 1997).

\section{Lipid peroxidation}

The increase in dietary lipid levels strongly correlated with the marked increase in malondialdehyde as a product of fatty acid peroxidation. A similar result was found with Senegalese sole (Rueda-Jasso et al. 2004). A geometrical relationship between degree of fatty acid unsaturation and fatty acid susceptibility to peroxidation was clearly established (Gray, 1977). Stephan et al. (1995) demonstrated that fish oil-enriched diets increased the susceptibility of turbot to fatty acid peroxidation, as estimated with thiobarbituric acid-reactive substance production and PUFA disappearance. In the present study, dietary PUFA were in relatively elevated percentages (37\%). With the increase in dietary lipids from 2 to $10 \%$, the amounts of PUFA ingested also increased, which represented a still greater pool of peroxidisable PUFA. Therefore, the increased production of thiobarbituric acid-reactive substances can be ascribed to increased dietary PUFA levels through oxidative breakdown of double bond-rich fatty acids. Peroxidation also produces reactive oxygen species, whose cellular damages may result in lowered enzymic activities and impaired membrane integrity (Winston \& Di Giulio, 1991; Halliwell \& Gutteridge, 1999). Indeed, the presence in liver of the L10 group of clusters of swollen cells strongly suggested that the peroxidation process was already sufficient to exert deleterious effects, at least on the most exposed hepatocytes. Mitochondria and peroxisomes should also constitute very sensitive targets for lipoperoxidation, which would result in decreased fatty acid oxidation rates and lower growth rates particularly in fish fed the L10 diet.

In summary, the herbivorous grass carp was shown to easily accept from $2 \%$ (the present study) to $4 \%$ (Du et al. 2005) lipid in the diet. With greater values, decreased growth performance, increased blood lipid peroxidation, alteration of lipoprotein synthesis and impaired mitochondrial and peroxisomal fatty acid oxidation capacities in liver were apparent. Dietary PUFA appear to be a crucial point of the susceptibility of herbivorous fish to fat-enriched diets. It would be interesting, as regards the present study and the aquaculture point of view, to determine whether DHA was actually responsible for the deleterious effects described in the L10 group using diets poorer in DHA and/or containing more antioxidants, such as $\alpha$-tocopherol.

\section{Acknowledgements}

We are grateful to Gui-Ying Liang for supplying healthy fish and Monique Baudoin for typing the manuscript.

\section{References}

Aebi H (1974) Catalase. In Methods of Enzymatic Analysis, pp. 673-684 [HU Bergmeyer, editor]. New York: Academic Press.

Arranz-Pena ML, Tasende-Mata J \& Martin-Gil FJ (1998) Comparison of two homogeneous assays with a precipitation method and an ultracentrifugation method for the measurement of HDL-cholesterol. Clin Chem 44, 2499-2505.

Arzel J, Martinez López FX, Métailler R, Stéphan G, Viau M, Gandemer G \& Guillaume J (1994) Effect of dietary lipid on growth performance and body composition of brown trout (Salmo trutta) reared in seawater. Aquaculture 123, 361-375.

Austreng E (1979) Fat and protein in diets for salmonid fishes. VI. Digestibility and feed utilization by rainbow trout (Salmo gairdneri Richardson) fed diets containing different levels of fat. Sci Rep Agric Univ Norway 58, 1-12.

Austreng E \& Krogdahl A (1987) Food quality of cultured salmonids can be influenced. Feedstuff 59, 12-14.

Bachorik PS \& Ross JW (1995) National cholesterol education program recommendations for measurement of low-density lipoprotein cholesterol. Clin Chem 41, 1414-1420. 
Bancroft JD \& Stevens A (1977) Theory and Practice of Histopathological Techniques. Edinburgh: Churchill Livingstone.

Beamish FWH \& Medland TE (1986) Protein sparing effects in large rainbow trout, Salmo gairdneri. Aquaculture 55, 35-42.

Bell JG, McEvoy J, Tocher DR, McGhee F, Campbell PJ \& Sargent JR (2001) Replacement of fish oil with rapeseed oil in diets of Atlantic salmon (Salmo salar) affects tissue lipid compositions and hepatocyte fatty acid metabolism. J Nutr 131, 1535-1543.

Berge GM \& Storebakken T (1991) Effect of dietary fat level on weight gain, digestibility, and fillet composition of Atlantic halibut. Aquaculture 99, 331-338.

Bilinski E \& Jonas EE (1970) Effects of coenzyme A and carnitine on fatty acid oxidation by rainbow trout mitochondria. J Fish Res Board Can 27, 857-864.

Bligh EC \& Dyer WJ (1959) A rapid method of total lipid extraction and purification. Can J Biochem Physiol 37, 911-927.

Bremer J (1981) The effect of fasting on the activity of liver carnitine palmitoyltransferase and its inhibition by malonyl-CoA. Biochim Biophys Acta 665, 628-631.

Cacerez-Martinez C, Cadena-Roa M \& Metailler R (1984) Nutritional requirements of turbot (Scophthalmus maximus): I. A preliminary study of protein and lipid utilization. J World Maricult Soc 15, 191-202.

Chen SH, Li SF, Liu ZS, Qiu QF \& Lin LK (1992) Application of Nuclear Technology in Biology, p. 61. Guangzhou, China: Zhongshan University Press.

Cho CY \& Kaushik SJ (1985) Effects of protein intake on metabolizable and net energy values of fish diets. In Nutrition and Feeding in Fish. Proceedings of International Symposium on Fish Feeding and Nutrition, pp. 95-117 [CB Cowey, AM Mackie and JG Bell, editors]. London: Academic Press.

Cho CY \& Kaushik SJ (1990) Nutritional energetics in fish: energy and protein utilization in rainbow trout (Salmo gairdneri). World Rev Nutr Diet 61, 132-172.

Clouet P, Niot I \& Bézard J (1989) Pathway of alpha-linolenic acid through the mitochondrial outer membrane in the rat liver and influence on the rate of oxidation. Biochem J 263, 867-873.

Demar JC, Ma K, Chang L, Bell JM \& Rapoport SI (2005) Alphalinolenic acid does not contribute appreciably to docosahexaenoic acid within brain phospholipids of adult rats fed a diet enriched in docosahexaenoic acid. J Neurochem 94, 1063-1076.

Dias J, Alvarez MJ, Diez A, Arzel J, Corraze G, Bautista JM \& Kaushik SJ (1998) Regulation of hepatic lipogenesis by dietary protein/energy in juvenile Eruopean seabass (Dicentrarchus labrax). Aquaculture 161, 169-186.

Dos Santos J, Burkow IC \& Jobling M (1993) Patterns of growth and lipid deposition in cod, Gadus morhua L., fed natural prey and fishbased feeds. Aquaculture 110, 173-189.

Du ZY, Liu YJ, Tian LX, Wang JT, Wang Y \& Liang GY (2005) Effect of dietary lipid level on growth, feed utilization and body composition by juvenile grass carp (Ctenopharyngodon idella). Aquacult Nutr 11, 139-146.

Forman BM, Chen J \& Evans RM (1997) Hypolipidemic drugs, polyunsaturated fatty acids and eicosanoids are ligands for PPAR alpha and delta. Proc Natl Acad Sci U S A 94, 4312-4317.

Frøyland L, Lie $\varnothing$ \& Berge RK (2000) Mitochondrial and peroxisomal $\beta$-oxidation capacities in various tissues from Atlantic salmon Salmo salar. Aquacult Nutr 6, 85-89.

Garling DL \& Wilson RP (1977) Effect of dietary carbohydrate to lipid ratio on growth and body composition of fingerling channel catfish. Prog Fish Cult 39, 43-47.

Gavino GR \& Gavino VC (1991) Rat liver outer mitochondrial carnitine palmitoyltransferase activity towards long-chain polyunsaturated fatty acids and their CoA esters. Lipids 26, 266-270.

Gaye-Siessegger J, Focken U, Abel H \& Becker K (2004) Dietary lipid content influences the activity of lipogenic enzymes in the liver and whole body delta $13 \mathrm{C}$ values of Nile tilapia, Oreochromis niloticus (L). Isotopes Environ Health Stud 40, 181-190.

Gjedrem T (1997) Flesh quality improvement in fish through breeding. Aquacult Int 5, 197-206.

Gordon T, Castelli WP, Hjortland MC, Kannel WB \& Dawber TR (1977) High density lipoprotein as a protective factor against coronary heart disease. Am J Med 62, 707-714.

Gray JI (1977) Measurement of lipid oxidation: a review. J Am Oil Chem Soc 55, 539-546.

Hagve TA \& Christophersen BO (1986) Evidence for peroxisomal retroconversion of adrenic acid (22:4(n-6)) and docosahexaenoic acids (22:6(n-3)) in isolated liver cells. Biochim Biophys Acta 875, $165-173$.

Halliwell B \& Gutteridge JMC (1999) Free Radicals in Biology and Medicine, 3rd ed., p. 936, Oxford: Clarendon Press.

Henderson RJ (1996) Fatty acid metabolism in freshwater fish with particular reference to polyunsaturated fatty acids. Arch Anim Nutr 49, 5-22.

Henderson RJ \& Tocher DR (1987) The lipid composition and biochemistry of freshwater fish. Prog Lipid Res 26, 281-347.

Hillestad M, Johnsen F, Austreng E \& Asgard T (1998) Long-term effects of dietary fat level and feeding rate on growth, feed utilization and carcass quality of Atlantic salmon. Aquacult Nutr 4, 89-97.

Hong DD, Takahashi Y, Kushiro M \& Ide T (2003) Divergent effects of eicosapentaenoic and docosahexaenoic acid ethyl esters, and fish oil on hepatic fatty acid oxidation in the rat. Biochim Biophys Acta $1635,29-36$.

Jacobs NJ \& Vandemark PJ (1960) The purification and properties of the alpha-glycerophosphate-oxidizing enzyme of Streptococcus faecalis. Arch Biochem Biophys 88, 250-255.

Johnsen F, Hillestad M \& Austreng E (1993) High energy diets for Atlantic salmon. Effects on pollution. In Fish Nutrition in Practice. Proceedings of the International Symposium on Fish Nutrition and Feeding, pp. 391-401 [SJ Kaushik and P Luquet, editors]. Paris: INRA.

Kaushik SJ \& Medale F (1994) Energy requirements, utilization and dietary supply to salmonids. Aquaculture 124, 81-97.

Kissileff HR \& van Itallie TB (1982) Physiology of the control of food intake. Ann Rev Nutr 2, 371-418.

Koditschek LK \& Umbreit WW (1969) Alpha-glycerophosphate oxidase in Streptococcus faecium. J Bacteriol 98, 1063-1068.

Latruffe N \& Vamecq J (1997) Peroxisome proliferators and peroxisomal proliferators activated receptor (PPARs) as regulators of lipid metabolism. Biochimie 79, 81-94.

Lee DJ \& Putnam GB (1973) The response of rainbow trout to varying protein/energy ratios in a test diet. $J$ Nutr 103, 916-922.

Lee SM, Jeon IG \& Lee JY (2002) Effects of digestible protein and lipid levels in practical diets on growth, protein utilization and body composition of juvenile rockfish (Sebastes schlegeli). Aquaculture 211, 227-239.

Lie Ø, Lied E \& Lambertsen G (1988) Feed optimization in Atlantic cod (Gadus morhua): fat versus protein content in the feed. Aquaculture 69, 333-341.

Lin D (1991) Grass carp, Ctenopharyngodon idella. In Handbook of Nutrient Requirements of Finfish, pp. 89-96 [RP Wilson, editor]. Boca Raton, FL: CRC Press.

Lin D, Mao Y \& Cai F (1990) Nutritional lipid liver disease of grass carp, Ctenopharyngodon idellus. Chin J Oceanol Limnol 8, 363-373.

Luzzana U, Serrini G, Moretti VM, Gianesini C \& Valfreá F (1994) Effect of expanded feed with high fish oil content on growth and fatty acid composition of rainbow trout. Aquacult Int 2, 239-248.

Madsen L, Frøyland L, Dyroy E, Helland K \& Berge RK (1998) Docosahexaenoic and eicosapentaenoic acids are differently metabolized in rat liver during mitochondria and peroxisome proliferation. J Lipid Res 39, 583-593. 
Mannaerts GP, Debeer LJ, Thomas J \& De Schepper PJ (1979) Mitochondrial and peroxisomal fatty acid oxidation in liver homogenates and isolated hepatocytes from control and clofibrate-treated rats. J Biol Chem 254, 4585-4595.

Martino RC, Cyrino JEP, Portz L \& Trugo LC (2002) Effect of dietary lipid level on nutritional performance of the surubim, Pseudoplatystoma coruscans. Aquaculture 209, 209-218.

Murai T, Takeuchi T, Watanabe T \& Nose T (1985) Effects of dietary protein and lipid levels on performance and carcass composition of fingerling carp. Bull Jpn Soc Sci Fish 51, 605-608.

Murata $H$ (1979) $\beta$-Oxidation of $22: 6$ acid in fish liver and dark muscle mitochondria. Bull Jpn Soc Sci Fish 45, 379-383.

Murata H \& Higashi T (1979) Studies on the metabolism of fatty acid in fish: rate of fatty acid decrease based on $\beta$-oxidation in carp dark muscle mitochondria. Bull Jpn Soc Sci Fish 45, 211-217.

Nakamura M, Taniguti Y, Yamamoto M, Hino K \& Manabe M (1997) Homogeneous assays of serum LDL-cholesterol on an automatic analyzer. Clin Chem 43, S260-S261.

Nanton DA, Lall SP, Ross NW \& McNiven MA (2003) Effect of dietary lipid level on fatty acid $\beta$-oxidation and lipid composition in various tissues of haddock, Melanogrammus aeglefinus L. Comp Biochem Physiol 135B, 95-108.

Peres H \& Oliva-Teles A (1999a) Influence of temperature on protein utilization in juvenile European sea bass (Dicentrarchus labrax). Aquaculture 170, 337-348.

Peres H \& Oliva-Teles A (1999b) Effect of dietary lipid level on growth performance and feed utilization by European sea bass juvenile (Dicentrarchus labrax). Aquaculture 179, 325-334.

Pullman DL, Liesman JS \& Emery RS (1990) A species comparison of liver slice synthesis and secretion of triacylglycerol from nonesterified fatty acids in media. J Anim Sci 68, 1395-1399.

Regost C, Arzel J, Cardinal M, Robin J, Laroche M \& Kaushik SJ (2001) Dietary lipid level, hepatic lipogenesis and flesh quality in turbot (Psetta maxima). Aquaculture 193, 291-309.

Ren B, Thelen AP, Petters JM, Gonzalez FJ \& Jump DB (1997) Polyunsaturated fatty acid suppression of hepatic fatty acid synthase and S14 gene expresstion does not require peroxisome proliferator activated receptor $\alpha$. J Biol Chem 272, 26827-26832.

Richmond W (1973) Preparation and properties of a cholesterol oxidase from Nocardia sp. and its application to the enzymatic assay of total cholesterol in serum. Clin Chem 19, 1350-1356.

Roeschlau P, Bernt E \& Gruber W (1974) Enzymatic determination of total cholesterol in serum. Clin Chem Clin Biochem 12, 226.

Rueda-Jasso R, Conceicao LEC, Dias J, De Coen W, Gomes E, Rees JF, Soares F, Dinis MT \& Sorgeloos P (2004) Effect of dietary non-protein energy levels on condition and oxidative status of Senegalese sole (Solea senegalensis) juveniles. Aquaculture 231, 417-433.

Ruyter B, Andersen $\varnothing$, Dehli A, Östlund F, Gjøen T \& Thomassen MS (1997) Peroxisome proliferator activated receptors in Atlantic salmon (Salmo salar): effects on PPAR transcription and acyl-CoA oxidase activity in hepatocytes by peroxisome proliferators and fatty acids. Biochim Biophys Acta 1348, 331-338.

Sargent JR, Bell JG, McEvoy L, Tocher DR \& Estevez A (1999) Recent developments in the essential fatty acid nutrition of fish Aquaculture 177, 191-199.

Schwartz MW, Baskin DG, Kaiyala KJ \& Woods SC (1999) Model for the regulation of energetic balance and adiposity by the central nervous system. Am J Clin Nutr 69, 584-596.

Silverstein JT, Shearer KS, Dickhoff WW \& Plisetskaya EM (1999) Regulation and nutrient intake and energy balance in salmon. Aquaculture 177, 161-169.
Smith PK, Krohn RI, Hermanson GT, Mallia AK, Gartner FH, Provenzano MD, Fujimoto EK, Goeke NM, Olson BJ \& Klenk DC (1985) Measurement of protein using bicinchoninic acid. Anal Biochem 150, 76-85.

Stephan G, Dreanno C, Guillaume J \& Arzel J (1996) Incidence of different amounts of proteins, lipids and carbohydrates in diets on the muscle lipid composition in the turbot (Scophthalmus maximus). Ichtyophysiol Acta 19, 11-30.

Stephan G, Guillaume J \& Lamour F (1995) Lipid peroxidation in turbot (Scophthalmus maximus) tissue: effect of dietary vitamin E and dietary n-6 or n-3 polyunsaturated fatty acids. Aquaculture 130, 251-268.

Stowell SL \& Gatlin DM III (1992) Effects of dietary pantethine and lipid levels on growth and body composition of channel catfish (Ictalurus punctatus). Aquaculture 108, 177-188.

Takeuchi T (1996) Essential fatty acid requirements in carp. Arch Tierernahr 49, 23-32.

Takeuchi T, Watanabe T \& Ogino C (1979) Availability of carbohydrate and lipid as dietary energy sources for carp. Bull Jpn Soc Sci Fish 45, 977-982.

Vamecq J, Vallee L, De la Porte PL, Fontaine M, De Cramer D, Van den Branden C, Lafont H, Grataroli R \& Nalbone G (1993) Effect of various n-3/n- 6 fatty acid ratio contents of high diets on rat liver and heart peroxisomal and mitochondrial $\beta$-oxidation. Biochim Biophys Acta 1170, 151-156.

van den Branden C, De Craemer D, Pauwels M \& Vamecq J (1995) Peroxisomes in mice fed a diet supplemented with low doses of fish oil. Lipids 30, 701-705.

Veerkamp JH, Van Moerkerk HT, Glatz JF \& Van Hinsbergh VW (1983) Incomplete palmitate oxidation in cell-free systems of rat and human muscles. Biochim Biophys Acta 753, 399-410.

Wang JT, Liu YJ, Tian LX, Mai KS, Du ZY, Wang Y \& Yang HJ (2005) Effect of dietary lipid level on growth performance, lipid deposition, hepatic lipogenesis in juvenile cobia (Rachycentron canadum). Aquaculture 249, 439-447.

Watanabe T (1982) Lipid nutrition in fish. Comp Biochem Physiol 73B, $3-15$.

Watanabe T, Takeuchi T \& Ogino C (1979) Studies on the sparing effect of lipids on dietary protein in rainbow trout (Salmo gairdneri). In Proceedings of World Symposium on Finfish Nutrition and Fishfeed Technology, pp. 113-125 [JE Halver and K Tiews, editors]. Berlin: Heenemann.

Weatherup RN, McCracken KJ, Foy R, Ride D, McKendry J, Maris RJ \& Hoey R (1997) The effects of dietary fat content on performance and body composition of farmed rainbow trout Oncorhynchus mykiss. Aquaculture 15, 173-184.

Weissbach H, Smith TE, Daly JW, Witkop B \& Udenfriend S (1960) A rapid spectrophotometric assay of mono-amine oxidase based on the rate of disappearance of kynuramine. J Biol Chem 235, $1160-1163$.

Winston GW \& Di Giulio RT (1991) Prooxidant and antioxidant mechanism in aquatic organisms. Aquat Toxicol 19, 137-161.

Xu RP, Hung SSO \& German JB (1993) White sturgeon tissue fatty acid compositions are affected by dietary lipids. J Nutr 123, $1685-1692$.

Yu SK, Olsen CE \& Marcussen J (1998) Methods for the assay of 1,5-anhydro-D-fructose and $\alpha$-1,4-glucanlyase. Carbohyd Res 305, 73-82.

Zheng WH, Liu YJ \& Tian LX (2002) A simple method for fatty acid analysis of fish liver. Chin J Health Lab Tech 2, 159. 